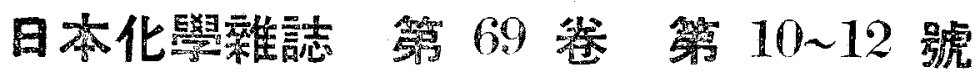

昭和 23 金 12 月

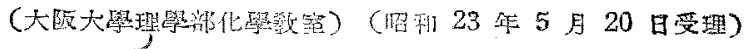

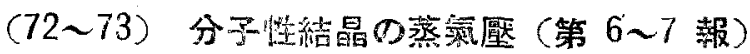

\section{仁 $\mathrm{CH}$

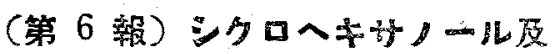 びシクロヘキサタン}

始に迅べるシクロへキサノールは Timmermanns 1

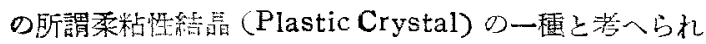

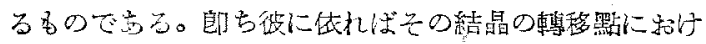

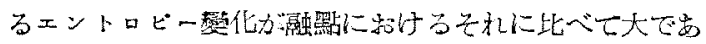

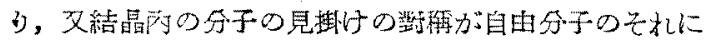
比べこ高く，乎于形の可成り舅なるものの間でしばしば

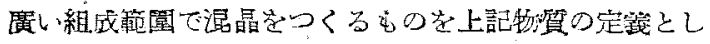

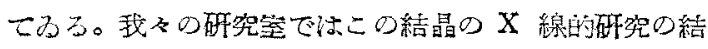

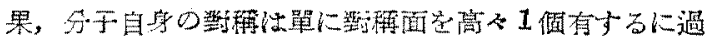
きないのに、結晶內では 通常のラウ土玨點以外に異常ラウ土散射のあること等が

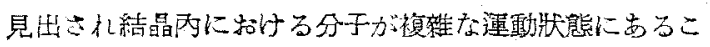

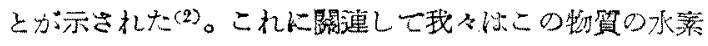

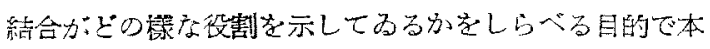

要・閣筑

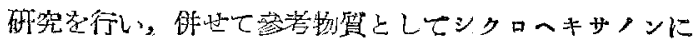

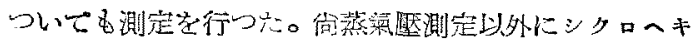

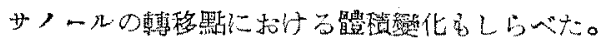

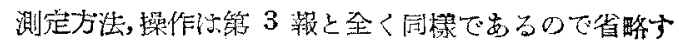

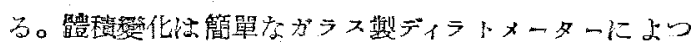
て行つた。比較填充液としては水銀を用いた。試数及び，

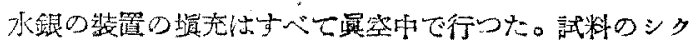

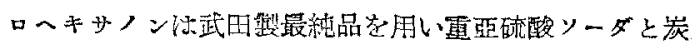

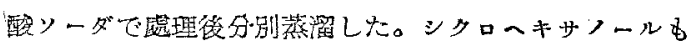

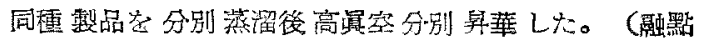
$\left.25.5 \sim 6^{\circ} \mathrm{C}\right)$ 。

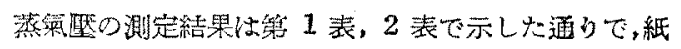

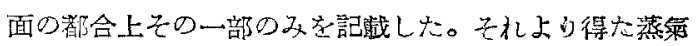

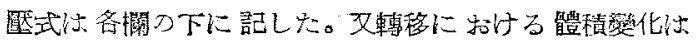
$\Delta V \approx 0.0367 \mathrm{cc} / \mathrm{g}$ ですり， $-30^{\circ}$ より $0^{\circ} \mathrm{C}$ までの體皘

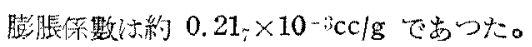

第 2 表

\begin{tabular}{|c|c|c|c|c|c|c|c|c|c|c|c|c|c|c|}
\hline \multicolumn{6}{|c|}{ 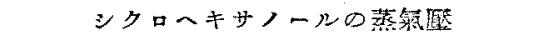 } & \multicolumn{9}{|c|}{ 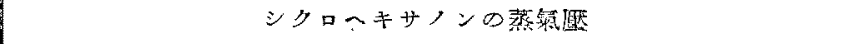 } \\
\hline & 固 & 相 & & 漼 & 相 & & 固 & 相 & & 液 & 相 & & 通泠 & 訨粗 \\
\hline No. & $1^{\circ} \mathrm{C}$ & $P \mathrm{mmHg}$ & No: & $t^{\circ} \mathrm{C}$ & $P \mathrm{mmHg}$ & No. & $t^{\circ} \mathrm{C}$ & $\mathrm{PmmHg}$ & No. & $t^{\circ} \mathrm{C}$ & $P \mathrm{mmHg}$ & No. & $\cdot 7^{\circ} \mathrm{C}$ & $P \mathrm{mmHg}$ \\
\hline 1 & -1.0 & 0.071 & 1 & 60.0 & 9.202 & $1:$ & -30.6 & 0.048 & 1 & 10.0 & 1. 490 & 1 & -29.3 & 0.031 \\
\hline 3 & +1.8 & 0.094 & 3 & 52.3 & 5.658 & 5 & -28.4 & 0.063 & 3 & 8.0 & 1.287 & 3 & -23.8 & 0.108 \\
\hline 5 & 3.9 & 0.113 & 5 & 46.1 & 3.626 & 7 & -26.7 & 0.074 & 5 & $6.1_{5}$ & 1.133 & 5 & -18.9 & 0.163 \\
\hline 7 & 5.9 & 0.138 & 6 & 43.0 & 2.919 & 13 & -19.3 & 0.143 & 7 & 3.9 & 0.968 & 7 & $-13.0_{i}$ & 0.262 \\
\hline 11 & 8.9 & 0.179 & 7 & 40.0 & 2.340 & 15 & -17.5 & 0.174 & 11 & -0.4 & 0.704 & 9 & -7.6 & 0.413 \\
\hline 15 & 12.5 & 0.254 & 8 & 37.0 & 1.885 & 17 & -16.1 & 0.194 & 15 & -3.5 & 0.556 & & & \\
\hline 19 & 16.0 & 0.338 & 9 & 33.0 & 1.400 & 19 & -15.6 & 0.200 & 19 & 4.9 & 1.037 & & & \\
\hline 23 & $20.0_{i}$ & 0.482 & 10 & $30.0_{s}$ & 1.080 & 23 & -13.9 & 0.234 & 23 & 18.7 & 2.721 & & & \\
\hline 29 & 22.9 & 0.607 & 11 & 27.9 & 0.906 & $2 \overline{5}$ & -10.4 & 0.319 & 27 & 31.9 & 6.126 & & & \\
\hline 32 & 24.45 & 0.697 & 12 & 26.1 & 0.790 & 27 & -8.6 & 0.374 & 28 & 25.5 & 4.174 & & & \\
\hline & $\begin{array}{r}P=\ldots \\
\quad+10\end{array}$ & $\begin{array}{c}3173.1 \\
7 \\
.506\end{array}$ & & $\begin{aligned} P & =-3 \\
& +10\end{aligned}$ & $\begin{array}{c}3142.4 \\
7 \\
402\end{array}$ & & $\begin{array}{r}P=-2 \\
+9.3\end{array}$ & $\begin{array}{c}576: 6 \\
\text { 'J' } \\
09\end{array}$ & & & -2 & & & \\
\hline
\end{tabular}




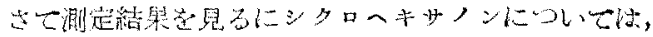

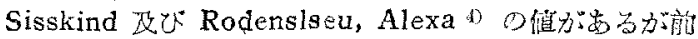

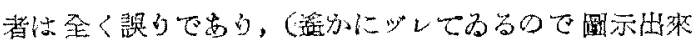

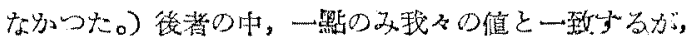

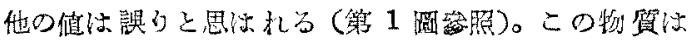

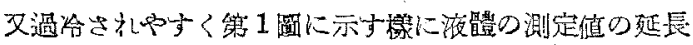
上に测定㥀力得られる。それ故 $-40^{\circ} \mathrm{C}$ 附近まて䋡々に

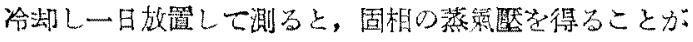

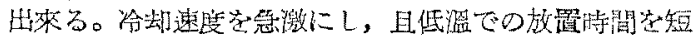

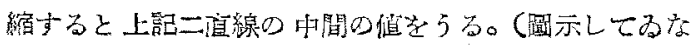

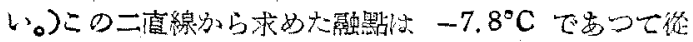

\section{第，1圆}

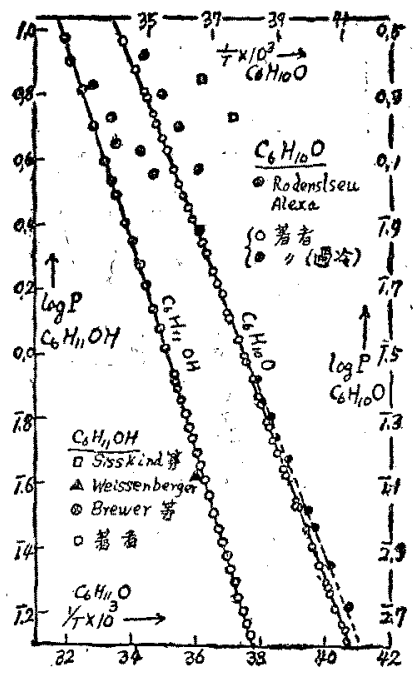

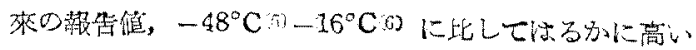

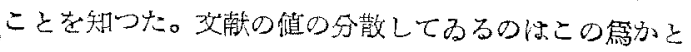
思仿礼る。

シタロヘキサノールについてる Sisskind の值は至～

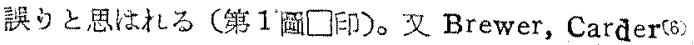

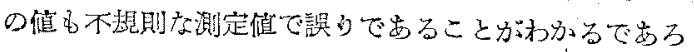

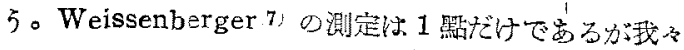
のものに近い。

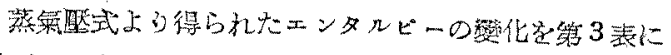

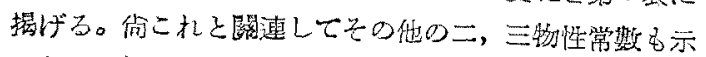

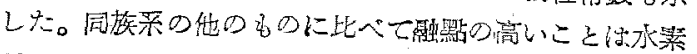

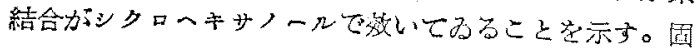

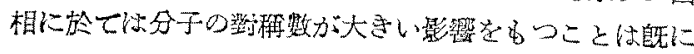
Deitz(8)に上り指摘された即であるが、几ーのタサール の骶县 $-47^{\circ} \mathrm{C}$ に比し，シクロへキサノールは $25.5^{\circ} \mathrm{C}$,
制 3 婊

\begin{tabular}{|c|c|c|c|c|}
\hline & $\begin{array}{c}\text { シタロ } \\
\text { チサ }\end{array}$ & 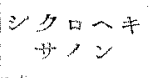 & 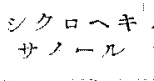 & $\begin{array}{l}x \neq n=y \\
n-\neq+3\end{array}$ \\
\hline 喓移琴 & $-87.01^{\circ} \mathrm{C}$ & - & $-9.6 t^{\circ} \mathrm{C}$ & $-\cdots$ \\
\hline 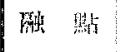 & $6.4 t^{\circ} \mathrm{C}$ & $-7.6 t^{\circ} \mathrm{C}$ & $23.51^{\circ} \mathrm{C}$ & $-126.3 \cdot{ }^{\circ} \mathrm{C}$ \\
\hline 沸 鼠占！ & $80.8 \div \mathrm{C}$ & $155.6{ }^{\circ} \mathrm{C}$ & $160 t^{\circ} \mathrm{C}$ & $99.9 \iota^{\circ} \mathrm{C}$ \\
\hline 拪移熱 & $1.6 \mathrm{I}$ & - & 1.96 & - \\
\hline 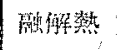 & 0.62 & 0.74 & $\left(\begin{array}{l}0.40 \\
0.14\end{array}\right.$ & 1.6 \\
\hline 是華篹I & 8.92 & 11.79 & 14.52 & 9.22 \\
\hline 蒸登䙪 & 8.09 & 11.05 & 14.38 & 8.60 \\
\hline 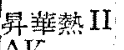 & 10.53 & - & 16.48 & - \\
\hline $\begin{array}{l}\Delta V_{m} \\
(\mathrm{cc} / \mathrm{g})\end{array}$ & 0.0627 & 0.046 & 0.025 & - \\
\hline$\left.\Delta V v^{\prime \prime}\right)$ & - & $\sim$ & 0.0367 & - \\
\hline$\mu$ & 0 & 2.75 & $1.9,1.7$ & - \\
\hline$a_{0}(\AA ̊ \AA)$ & 8.76 & 8.78 & 8.79 & - \\
\hline \multicolumn{5}{|c|}{ 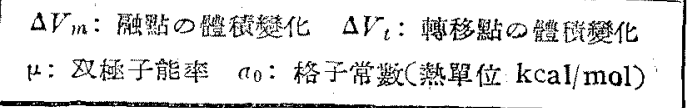 } \\
\hline
\end{tabular}

nーヘキサンの融影 $-95^{\circ} \mathrm{C}$ に比し，シクロヘキサン $6.4^{\circ} \mathrm{C}$ ¿山。

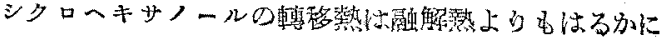
大きいがこれは先にのべ柔粘性結晶の国目等示して

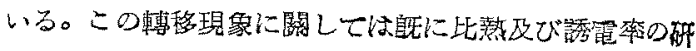
究が各り，入望轉移て怘ることが知られてるる。目由分

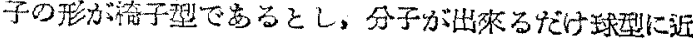
い形として， $\mathrm{OH}$ 㫷の位置若慮しシクロへキ甘ン摆の 中心が面心立方格于の格子黠に一致するものと假定して

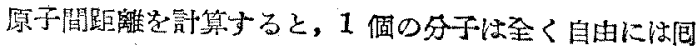

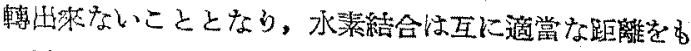

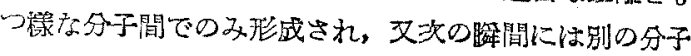
と形成される如き6のと考无られる。佮轉移に和ける體

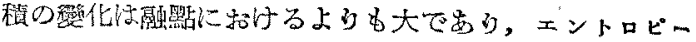

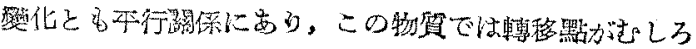

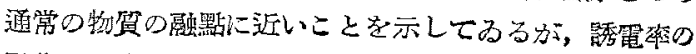

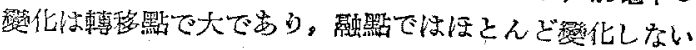
ことるこの聚安物語つている。

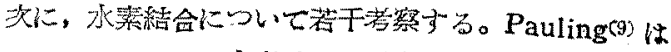

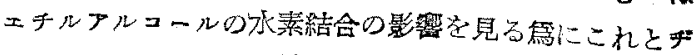
メチルェーテルとの比較を行つているが，水素結合のx ネルギー效果を見るには $-\mathrm{OH}$ と同霞子數の $-\mathrm{CH}_{3}$ を

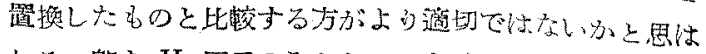
れる。郎か $\mathrm{H}$ 原子のみとしてでなく 相互作朋として見るならば，ェーテルの双極子能管の 


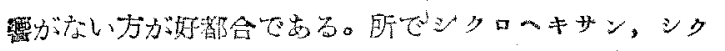

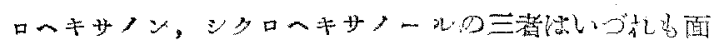

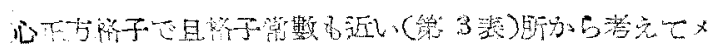

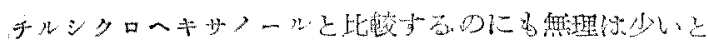

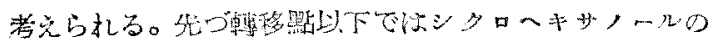

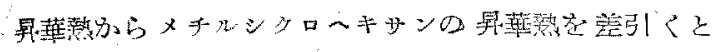

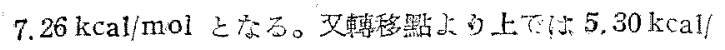

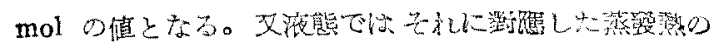

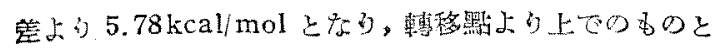

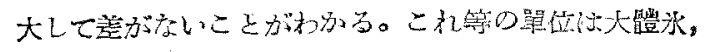
アルンール類のるのと同程宸でることがわかるのです

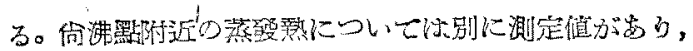
$14.38 \mathrm{kcal} / \mathrm{mol}$ 方ら $11.7 \mathrm{kcal} / \mathrm{mol}$ をで娍少している。

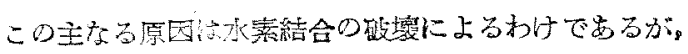
メチルシタローキサンの沸點附近のそれと比较すると，

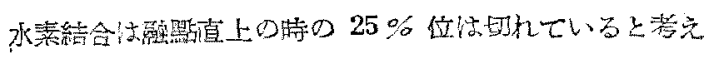

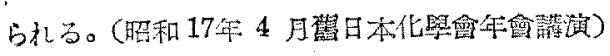

\section{(第 7 報)フェノールの蒸氣型}

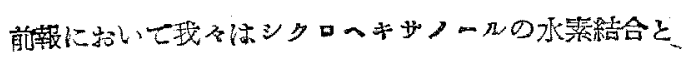

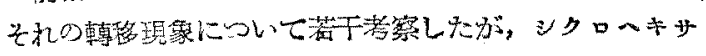

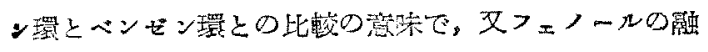

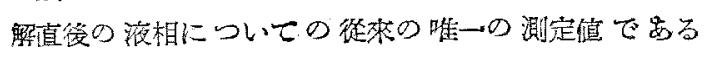

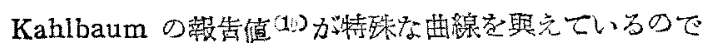

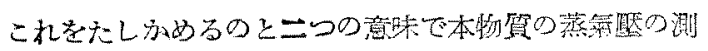
定を行つた。

第

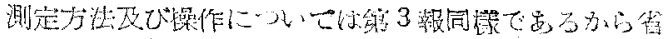

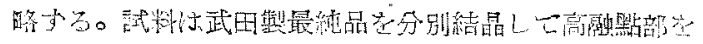

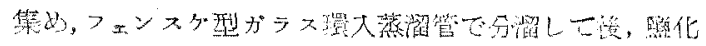

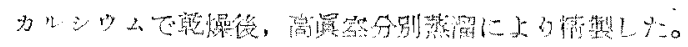

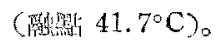

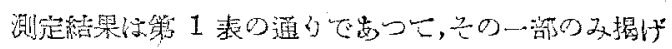

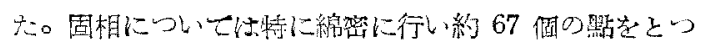

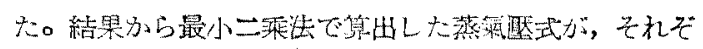

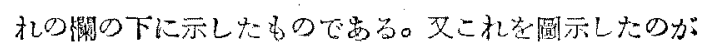
第 1 圆でする。

第 1 圆

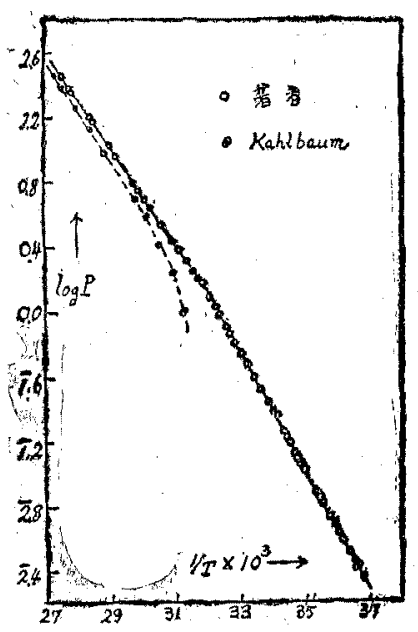

表

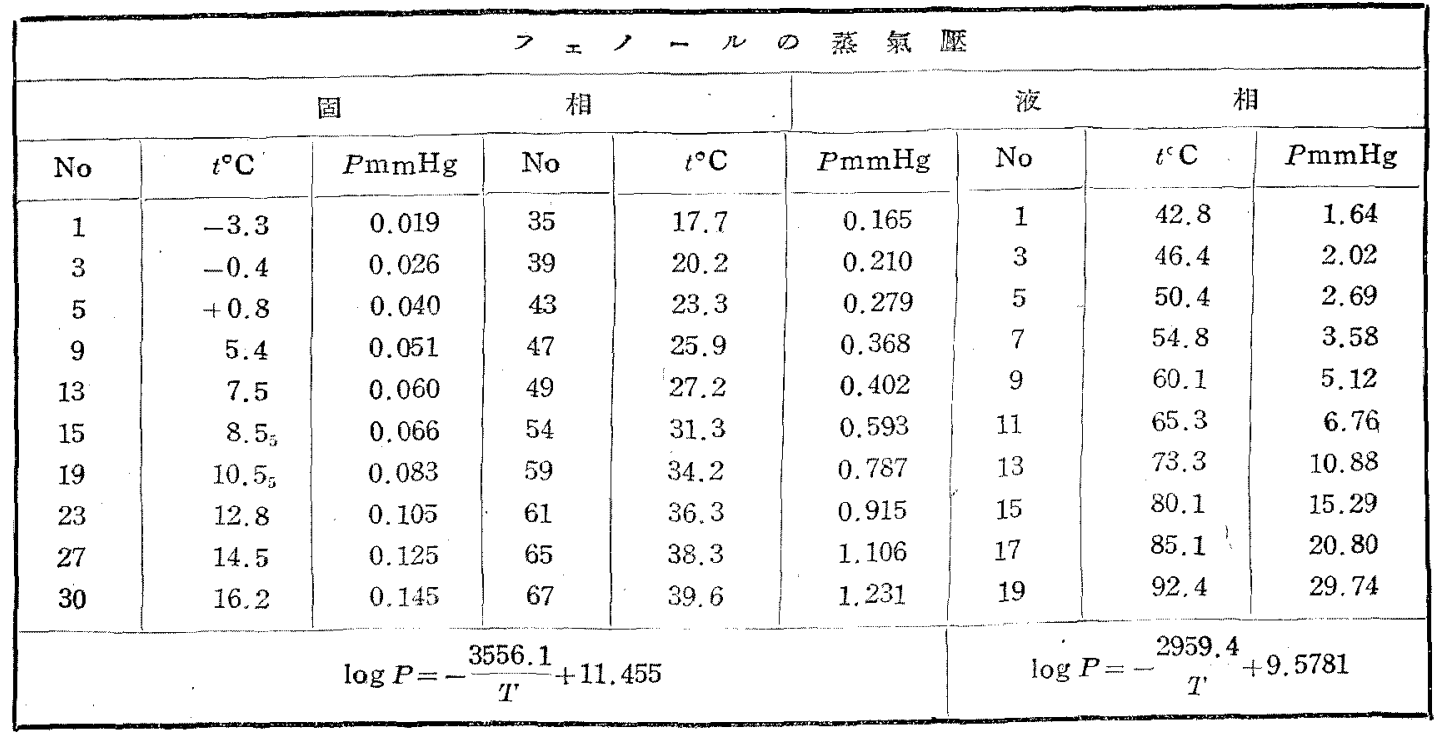

